\title{
Macrothrombocytopenia with mitral valve insufficiency
}

INSERM

\section{Source}

INSERM. (1999). Orphanet: an online rare disease and orphan drug data base.

Macrothrombocytopenia with mitral valve insufficiency. ORPHA:220448

Macrothrombocytopenia with mitral valve insufficiency is a rare hemorrhagic disorder due to a platelet anomaly characterized by dysfunctional platelets of abnormally large size, moderate thrombocytopenia, prolonged bleeding time and mild bleeding diathesis (ecchymoses and epistaxis), associated with mitral valve insufficiency. 